This article was downloaded by:[EPFL Lausanne]

On: 24 April 2007

[EPFL Lausanne]

Access Details: [subscription number 768419380]

Publisher: Taylor \& Francis

Informa Ltd Registered in England and Wales Registered Number: 1072954

Registered office: Mortimer House, 37-41 Mortimer Street, London W1T 3J H, UK

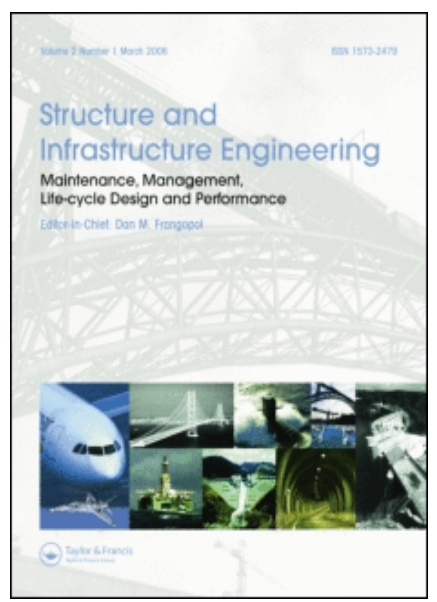

Structure and Infrastructure Engineering Maintenance, Management, Life-Cycle Design and Performance

Publication details, including instructions for authors and subscription information: http://www.informaworld.com/smpp/title content=t713683556

Assessment of existing steel structures. A guideline for estimation of the remaining fatigue life

Rosemarie Helmerich ${ }^{a}$; Bertram Kühn ${ }^{a}$; Alain Nussbaumer ${ }^{a}$

${ }^{a}$ RosemarieHelmerichBertramKühnAlainNussbaumerF ederal Institute for Materials Research and Testing, Division IV.4 Non-Destructive Damage Assessment and Environmental Measurement Methods, Unter den Eichen 87, D-12205, Berlin, GermanyConsultancy PSP, P rof. Sedlacek \& Partner, Planung und Entwicklung im Bauwesen $\mathrm{G} \mathrm{mbH}$, Lagerhausstr. 27, 52064, Aachen, GermanyE cole Polytechnique Fédérale de Lausanne (EPFL), Laboratoire de la Construction Métallique (ICOM), Bâtiment GC B3, Faculté ENAC, $\mathrm{CH}-1015$, Lausanne, EPFL, Switzerland.

First Published on: 03 April 2006

To cite this Article: Rosemarie Helmerich, Bertram Kühn and Alain Nussbaumer, 'Assessment of existing steel structures. A guideline for estimation of the remaining fatigue life', Structure and Infrastructure Engineering, 1

To link to this article: DOI: $10.1080 / 15732470500365562$

URL: http://dx.doi.org/10.1080/15732470500365562

PLEASE SCROLL DOWN FOR ARTICLE

Full terms and conditions of use: http://www.informaworld.com/terms-and-conditions-of-access.pdf

This article maybe used for research, teaching and private study purposes. Any substantial or systematic reproduction, re-distribution, re-selling, loan or sub-licensing, systematic supply or distribution in any form to anyone is expressly forbidden.

The publisher does not give any warranty express or implied or make any representation that the contents will be complete or accurate or up to date. The accuracy of any instructions, formulae and drug doses should be independently verified with primary sources. The publisher shall not be liable for any loss, actions, claims, proceedings, demand or costs or damages whatsoever or howsoever caused arising directly or indirectly in connection with or arising out of the use of this material.

(c) Taylor and Francis 2007 


\title{
Assessment of existing steel structures. A guideline for estimation of the remaining fatigue life
}

\author{
ROSEMARIE HELMERICH*†, BERTRAM KÜHN† and ALAIN NUSSBAUMER $\S$ \\ $\dagger$ Federal Institute for Materials Research and Testing, Division IV.4 Non-Destructive Damage Assessment and \\ Environmental Measurement Methods, Unter den Eichen 87, D-12205 Berlin, Germany \\ †Consultancy PSP, Prof. Sedlacek \& Partner, Planung und Entwicklung im Bauwesen GmbH, \\ Lagerhausstr. 27, 52064 Aachen, Germany \\ $\S$ Ecole Polytechnique Fédérale de Lausanne (EPFL), Laboratoire de la Construction Métallique (ICOM), \\ Bâtiment GC B3, Faculté ENAC, CH-1015 Lausanne EPFL, Switzerland
}

(Received 21 February 2005; accepted in revised form 20 September 2005)

\begin{abstract}
In many countries and regions, traffic infrastructure projects suffer from low funding. The budget is tight for new infrastructure building and, thus, the importance of inspection, maintenance and assessment of the existing traffic infrastructure increases. A new fatigue assessment guideline for the estimation of the remaining fatigue life of steel bridges has been written by technical committee 6 from ECCS. It will be a useful tool for the complementation of bridge management systems, used commonly for condition assessment.

Design specifications and rules are harmonised throughout Europe. They are under constant development, but there is still a lack of forwarding and concentrating experiences as well as developing rules for the fatigue assessment on existing steel structures. This paper presents a guideline with a proposed fatigue assessment procedure for existing steel structures embedded in information about old materials and nondestructive testing methods for the evaluation of details (ECCS 2004, Assessment of existing steel structures). Particular attention is paid on remedial measures which are proposed for weak details and damages caused by fatigue. The developed fatigue assessment procedure can be applied to existing steel structures under cyclic loading in general, but the guideline concentrates on the existing traffic infrastructure made from old steel, because of the public importance. The proposed procedure summarizes, regroups and arranges the knowledge in the field of assessment on existing steel to be applied by practicing engineers. The procedure is a milestone in knowledge transfer from a state of scientific knowledge to state-of-the-art.
\end{abstract}

Keywords: Fatigue; Assessment; Maintenance; Reliability; Material; Old steel; Remedial measures; Existing steel structures

\section{Introduction}

In 1993, the technical committee 6 of the European Convention of Constructional Steelwork (ECCS), created the working group "Remaining fatigue life", with the objective to concentrate the knowledge and experiences for the fatigue assessment on existing steel structures in a guideline. Up to 2000, the work has been coordinated by Klaus Brandes from the Federal Institute for Materials Research and Testing (BAM). Since that time, Bertram Kühn from Professor Sedlacek \& Partner, PSP Aachen, as the new leader of the working group, supervised the work on the new recommendation for the assessment of existing steel bridges.

\footnotetext{
*Corresponding author. Email: rosemarie.helmerich@bam.de

Structure and Infrastructure Engineering 
During the last decades, the inspection of the existing bridge stock and the condition assessment procedures have been increasingly well organised. In many countries bridge management systems have been introduced. Nevertheless, a guideline for assessing the fatigue safety will be of interest for many owners of old steel and iron bridges. The presented recommendation focuses on analysis of fatigue safety, on old material identification and rehabilitation. Once it is recognised that the damage is caused by fatigue, targeted repair and strengthening measures can be decided upon. The tasks involved are clearly defined by explaining the general applicability of the remedial measures for steel structures exposed to fatigue loading, as described in this recommendation.

With the rapid development of new materials and new calculation methods in the second half of the 19th and turn of the 20th century, many steel bridges were built, of which many are still in use today. The old materials are not commonly known anymore and sometimes the remaining fatigue life is difficult to estimate. Effectively, on one hand the assessment of fatigue safety was not included in the design at the turn of the 19th to 20th century. Often, especially for road bridges, the load history was not reported. On the other hand, some changes in the structure after repair or strengthening measures within the last hundred years were not indicated in the drawings. Other information got lost during the two world wars. Sometimes the loading of a bridge had to be increased drastically or even a new lane was added. In all these cases, a fatigue assessment is compulsory.

For the estimation of the structures, the current fatigue resistance and the remaining fatigue life, applying traditional calculation, the analysis of the load spectrum, e.g. in terms of accumulated damage in the past, is important. If a crack is found or the load history is not known, new methods can be applied, e.g. the fracture mechanic approach (FMA). FMA is neglecting the crack initiation phase, which represents a high percentage of the whole fatigue life of a structure. However, in spite of it, FMA can replace traditional calculation methods to show that a positive remaining fatigue life exists, even when the previous load history is not known.

\section{Assessment procedure}

\subsection{Limitation}

The fatigue assessment of an existing structure results in a statement about the safety of the structure under cyclic loading for a specified remaining fatigue life. The application of the recommendation presented herein is restricted to structures under normal environmental conditions and temperatures between -40 and $150^{\circ} \mathrm{C}$. Assessment of structures exposed to fire is not considered. Assessment under low cycle fatigue, as during seismic activities, is not included either. Finally, the assessed element itself must be inspectable.

\subsection{Fatigue assessment procedure}

For the fatigue assessment, a step-by-step procedure is proposed. The proposed stepwise procedure is based on a general procedure developed by the Joint Committee for Structural Safety (JCSS) and published in 2001, which was further enhanced with focus on existing steel bridges exposed to fatigue loading. If the assessment using this procedure proves a sufficient remaining fatigue life in one of the early phases, the later following phases can be disregarded. The assessment consists in the application of the following proposed phases.

I. Preliminary Evaluation. Removal of existing doubts about safety of the structure using fairly simple methods. Information from visual inspection, including, for example, information from Bridge Management Systems (BMS) and own inspection on site. The owner is informed in a first report.

II. Detailed investigation. The engineer may need the help of specialised laboratories and experts for assistance. Information on the structure and loadings are updated using specific tools as refined calculation models or more realistic traffic loads. If the result is negative, different proposals can be given to the owner in a second report.

III. Expert investigation. A refined static model is used for probabilistic evaluation and fracture mechanics for establishing final decisions. Measurements help to obtain refined data from the structure and about loading. Advanced NDT may be used in cross sections specified with the updated model. An expert report informs the owner.

IV. Remedial measures. Making the structure fit for purpose again by using special measures such as intensifying monitoring, reduction of loads, change in use, strengthening, repair or rehabilitation. A final report summarises the results of all working steps. All remedial measures, possible from the technical point of view are proposed. The report will give all information, which the owner of the structure needs for an economical decision about further measures.

Often, the use of the step-by-step procedure leads to extending the lifetime and to postpone investments in new bridges. It also clarifies whether a bridge is safe without any further measures, or whether it is no longer sufficient and needs to be reinforced or demolished. The stepwise procedure presented in the guideline (figure 1 (ECCS 2004)) helps to find the best strategy for the optimal life cycle costs. 


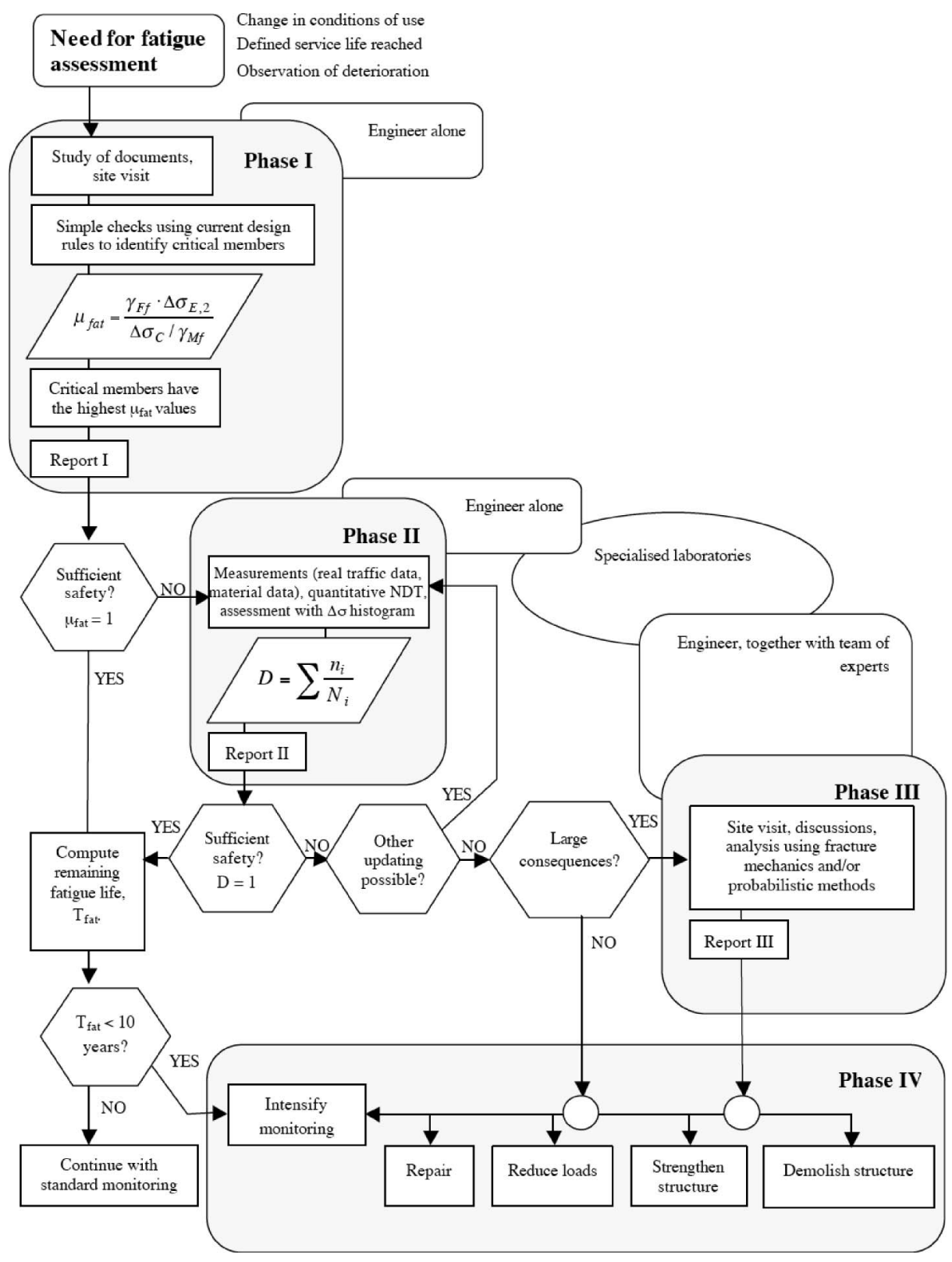

Figure 1. Stepwise procedure for fatique assessment.

The guideline gives detailed information about each step of the fatigue assessment procedure. Phase I uses the conservative data as input into the $\mathrm{S}-\mathrm{N}$-curve approach. The detail category, which is proposed for the assessment of riveted structures, was confirmed in many full-scale tests worldwide. For the load history, a conservative estimation is used. As shown in figure 1, for the fatigue limit state, the fatigue safety ratio $\mu_{\mathrm{fat}}$ is introduced. The most critical details have the lowest safety ratio. The safety level can be expressed as follows:

$$
\mu_{f a t}=\frac{\gamma_{F f} \cdot \Delta \sigma_{E, 2}}{\Delta \sigma_{C} / \gamma_{M f}}
$$

$\mu_{\text {fat }} \quad$ fatigue safety ratio

$\gamma_{\text {fat }}$ partial safety factor for equivalent constant amplitude stress range

$\Delta \sigma_{\mathrm{E}, 2}$ equivalent constant amplitude stress range related to 2 million cycles

$\Delta \sigma_{\mathrm{C}}$ reference value of the fatigue strength at 2 million cycles (detail category)

$\gamma_{\mathrm{Mf}}$ partial safety factor for fatigue strength $\Delta \sigma_{\mathrm{C}}$ 
$\Delta \sigma_{\mathrm{C}}$ is assumed to be the fatigue strength of $71 \mathrm{~N} / \mathrm{mm}^{2}$ at 2 million stress cycles. A bilinear $\mathrm{S}-\mathrm{N}$ curve (general relationship $\Delta \sigma^{\mathrm{m}} N=$ cte (Eurocode 3,2003$)$ ) is used with a slope $m$ equal to 3 between 0 and 5 million cycles and a slope $m$ equal to 5 between 5 and 100 million cycles. An equivalent constant amplitude fatigue limit $\Delta \sigma_{\mathrm{E}, 2}=52 \mathrm{~N} /$ $\mathrm{mm}^{2}$ was proved to exist for old steel bridges at 5 million cycles, if the stress range has never passed this limit during the whole service life of the bridge (Crocetti 1999). Stress ranges of the design spectrum do not contribute to the cumulative damage, if they are below the cut off limit of $29 \mathrm{~N} / \mathrm{mm}^{2}$.

In Phase II, detailed investigation is made to update the information obtained in Phase I using refined input data for the structural model, applied loads and dynamic amplification factors. In well-identified cases, for example heavy corrosion, ultrasonic measurements can be used to obtain information on the remaining cross-section area. In specified details critical to fatigue loading, the remaining fatigue life is estimated by means of the Palmgren-Miner damage accumulation rule (Miner 1945):

$$
\sum \frac{n_{i}}{N_{i}}=1
$$

$n_{i} \quad$ actual number of cycles at stress range $i$

$N_{i}$ theoretical fatigue life at stress range $i$.

If the $\mathrm{S}-\mathrm{N}$-curve assessment results in insufficient remaining fatigue life, an expert investigation according to Phase III has to be carried out. It includes measurements, advanced material testing and NDT as well as the application of a fracture mechanics approach (FMA). FMA is proposed after a crack is detected or if a crack, just not detectable using NDT, is postulated. FMA is also applied, if the load history is not available for the evaluated detail. Using this method, safe service intervals can be calculated. Paris law describes the stable crack propagation using material-specific characteristics. Paris law is applied in connection with the cyclic stress intensity factor $\Delta K$, see equation (3). The material constants $\mathrm{m}$ and $\mathrm{C}$, as well as the threshold value of the stress intensity factor, can be obtained from normalised crack propagation tests and then used to calculate the stable crack growth period before the stress intensity does not exceed a critical value at the critical crack length $a_{\mathrm{c}}$. The results of Phase III are presented to the bridge owner in a report for further decisions.

$$
\Delta \mathrm{K}=\mathrm{Y}^{*} \Delta \sigma \sqrt{\pi^{*} \mathrm{a}}
$$

$\Delta \sigma \quad$ applied cyclic stress range

$Y$ geometry factor (usually taken from data books, e.g. Murakami)

$\Delta K$ cyclic stress intensity factor

$a \quad$ crack length
The recommendation will serve as a basis for defining inservice inspection intervals. After the end of each interval, an inspection will be carried out and the critical details will be controlled regarding the existence of fatigue cracks. If no cracks are found, the bridge is declared safe until the next inspection. In other cases when cracks were found, remedial actions have to take place. This can consist of removing the cracks or stopping them using stop holes. However, the situation could occur where more time is necessary to design appropriate repair and/or strengthening measures, and so the crack length can be measured and with this information a new shorter inspection interval can be set (Hensen 1992).

The assessment of the reliability of the structure during residual service life can be estimated using risk acceptance criteria in Phase IV, which depend on the consequences of a failure. The accepted risk is discussed depending on the redundancy, the social-political importance of the structure and the inspection level. Hints on the set up of the reliability index $\beta$ and the probability of failure over the time are given. For more details see ECCS (2004).

The results of Phase IV are presented to the bridge owner in a final report and used for taking decisions, such as intensifying monitoring, repairing, strengthening or demolishing the structure.

\section{Obtaining information from the structure}

\subsection{Introduction}

To get information on the resistance of a structure, both field measurements and/or material investigation are used to obtain the information directly from the structure itself. Data characterizing the old steel, design rules or connections between elements differ noticeably from today's standards. That is why design, materials database, calculations and drawings as well as additional experiences must be studied first.

\subsection{Material identification}

Several sources can be used to get information about the resistance characteristics of the used material, for instance:

- yield and ultimate strength, $R_{m}, R_{e L}, R_{e H}$,

- Young's Modulus, E,

- chemical analysis, C, Si, Mn, P, S, N,

- analysis of the microstructure, or

- crack propagation law constants.

In Phase I the material data can be obtained from old design documents or from old delivery standards for steel.

If sufficient safety cannot be determined in Phase I, in Phase II, the assessing engineer can profit from statistical 
evaluated data on old steel, given in ECCS (2004) or-if not planned in Phase III-from standard material testing on small specimens. The cross section must not be reduced significantly. From sections with low stress levels, only small specimens can be taken carefully. Only educated engineers are allowed to take material from the structure. In figure 2, sampling is shown (e.g. by sawing or using a drilling machine attached to the steel structure by means of an electromagnetic foot). If the sample is long enough, flat tension test specimens with a rolled surface at least on one side can be used in a tension test. Sampling by sawing is possible. Flame cutting concentrates impurities as sulphur or phosphates in the heat-influenced zone and may cause convenient conditions for future damage, which is why flame cutting has to be prohibited.

During sampling, the requirements of EN 10025 must be considered. For the evaluation of material data of beams where samples were taken from the web, one must consider that the distribution of strength over the cross section differs. The yield and tension strength are higher in the web of beams than in their flanges. The minimum diameter for a test specimen from modern steels must not fall below $4 \mathrm{~mm}$. For old iron, because of segregations and layered structure, the strict minimum recommended for test specimen diameter is $5 \mathrm{~mm}$.

The material used for old riveted structures differs significantly from modern steel. The recommendation (ECCS 2004) explains the differences between the old materials and gives hints on how to identify the materials.

The production process influences the material properties significantly. In Coalbroakdale (UK), the first cast-iron bridge was built in 1779 and is still in use today. Wrought iron was used by the Romans and in the Middle Ages by blacksmiths. In 1784, Henry Cort developed the puddling process, in which the iron ore and coke were kept separate in the furnace. The raw iron was deoxidised in the puddling process. By using coke, the content of carbon was reduced to less than $1.7 \%$. In the late 18 th and 19 th centuries, wrought or puddled iron was used for bridges. Nineteenth century rolled wrought iron produced by puddling is known as "puddled iron". Both terms (wrought and puddled iron) are used for the early bridge iron. The puddled iron was very expensive because of the laborious forging process. The first Tay Bridge, which collapsed in 1879 , was built as a lattice girder bridge supported by castiron columns and braced with wrought-iron struts and ties. Insufficient design of the wind bracing, storm and low temperature were assumed to be the causes of the disaster. Some iron bridges are still in use today, but most have already been exchanged to widen streets or to allow higher axle loads.

Puddled iron has been produced for more than 130 years, but in 1913, the production of puddled iron was reduced to $1.3 \%$ of the whole world steel production. The microstructure of puddled iron (see figure 3 ) is characterised by a layered cross section resulting from the rolling and looping process. The mineral impurities are mostly silica slag. The iron grains between the slag layers are large. The sulphurous print visualises the sulphur included in the slag layers. The layered microstructure of puddled iron is the reason for the anisotropic behaviour. Wrought iron has a low tension strength perpendicular to the rolling direction. The tension strength of rolled members is tested in rolling direction, which is comparable to the values given in the delivery standards. Web plates were probably packed and rolled in two directions to have better behaviour under

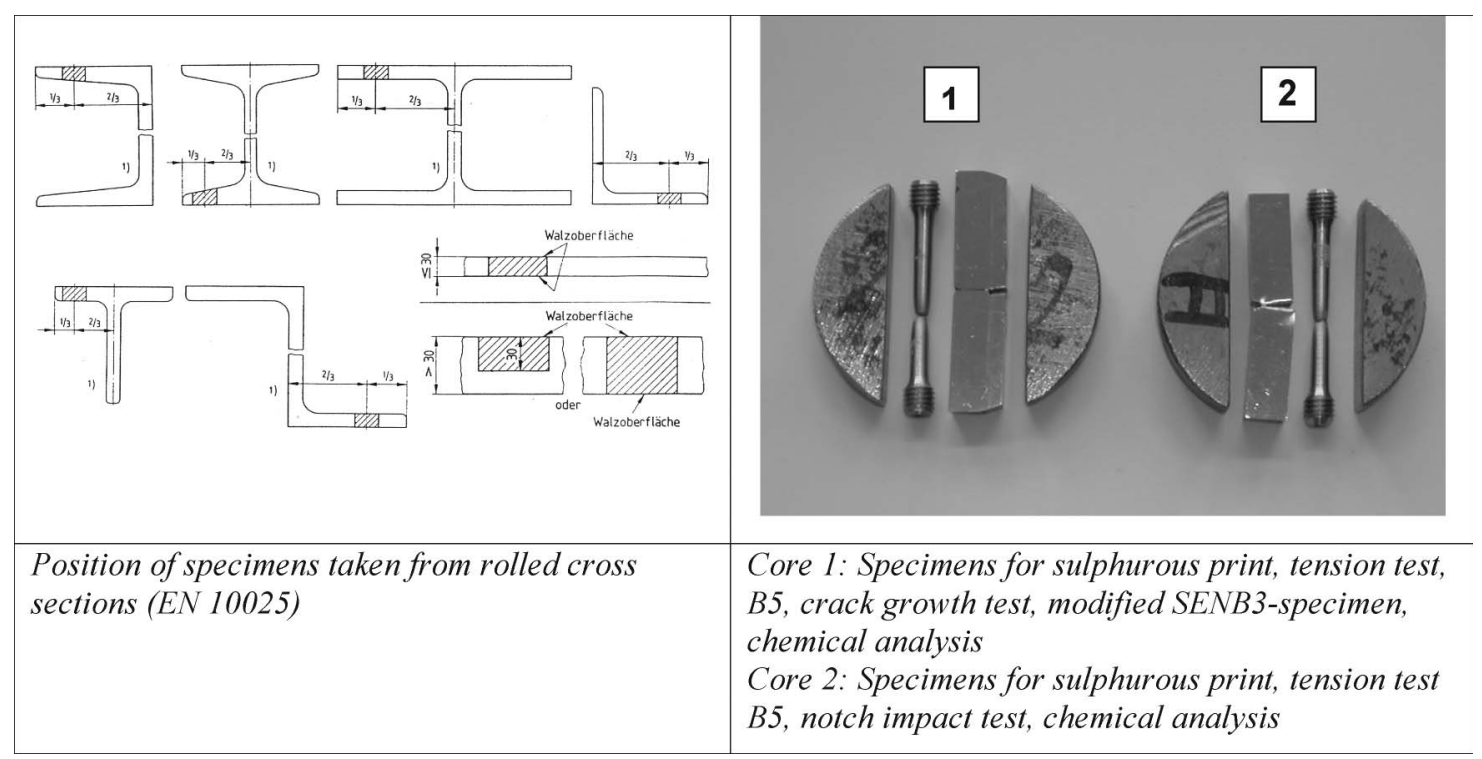

Figure 2. Sampling in rolled cross sections and example for distribution of test specimens in the drilled sample. 
more dimensional load. The iron layer between the slag layers characterises a low content of carbon.

In tension test the macroscopic elongation is quite good. For puddled iron, necking as a local strain effect typically does not occur. The chemical analysis has to be made by wet analysis since it is impossible by emission spectroscopy.

Early mild iron or steel is a low carbon iron/steel, known as rimmed steel, characterised by low carbon content $<0.15 \%$, often $<0.1 \%$, and by sulphurous segregations. It is produced by melting cast iron and removing slag and carbon in a converter, following Bessemer, who in 1856 developed a converter for liquefaction of iron due to lowering the content of carbon (oxidation) in the iron mass. When pouring the liquid iron into the ingots, the iron forms a "rim" on the bottom and the walls and remains liquid at the top. The ingredients such as sulphur and phosphor remain concentrated in the slow hardening regions. The resistance against corrosion is lower than that of puddled or wrought iron. Thomas and Siemens (1864) improved the process using an alkaline brick lining inside the converter to reduce the phosphate impurities. The processing temperature was much higher than in earlier processes. The resulting yield strength and Young's modulus of this more homogeneous material were higher. Early mild iron can reduce local re-strain in structures because of its ability of local plasticity. Figure 4 shows a specimen after a tension test with significant necking and a characteristic sulphurous print. The terminology for mild iron/steel differed a lot depending on the regions and countries. Unified terms were introduced with the ongoing standardisation after World War II in the 20th century.

In the 20th century, modern steel was produced. The steel was killed (deoxidised) using silicates or aluminium to quiet the molten metal. The result is a smaller regular grain microstructure, the cold- or hot-rolled sections have a homogeneous structure and a negligible small segregation zone. As a result of higher manganese content, the material is harder, has a higher yield and ultimate strength, and is weldable. In general, the content of carbon in modern steel, used for structural engineering, is between 0.15 and $0.25 \%$. Today, hot-galvanising increases the insufficient resistance of the modern structural steel against corrosion, but detailing of these components must be well designed to avoid possible cold cracking problems.

For the material data collection given below, puddle and wrought iron from German bridges and structures were investigated. The data are an orientation for the practising engineer. A European or even world-wide material database might deliver slightly different values. For lower temperatures, the yield strength is assumed to be approximately $3.5 \%$ higher. Table 1 summarizes the data obtained at $10^{\circ} \mathrm{C}$ or ambient room temperature.

Compared to wrought iron or rimmed steel, one should note that stable crack growth in modern steels is slower;

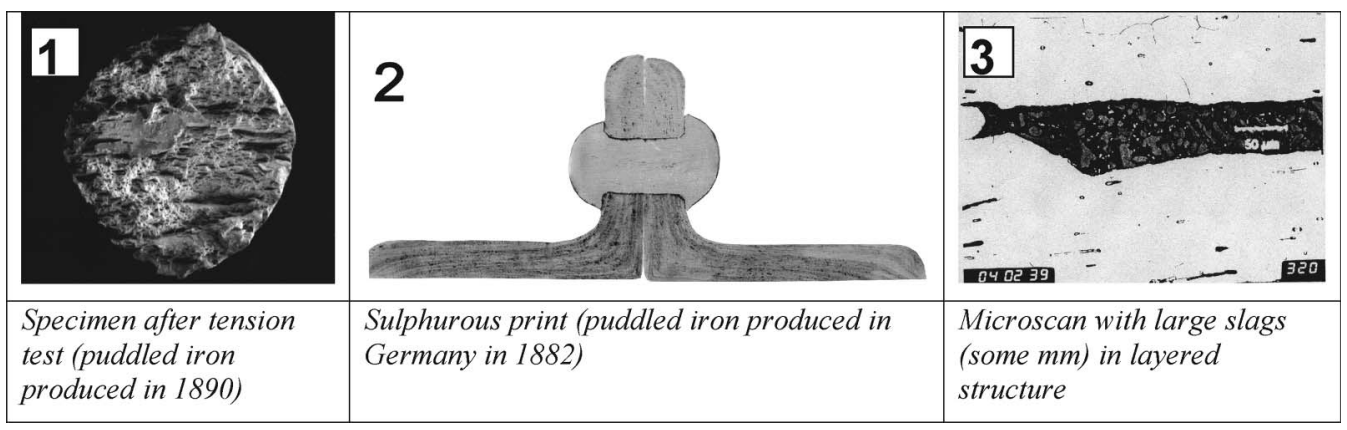

Figure 3. Characteristics of puddled iron.

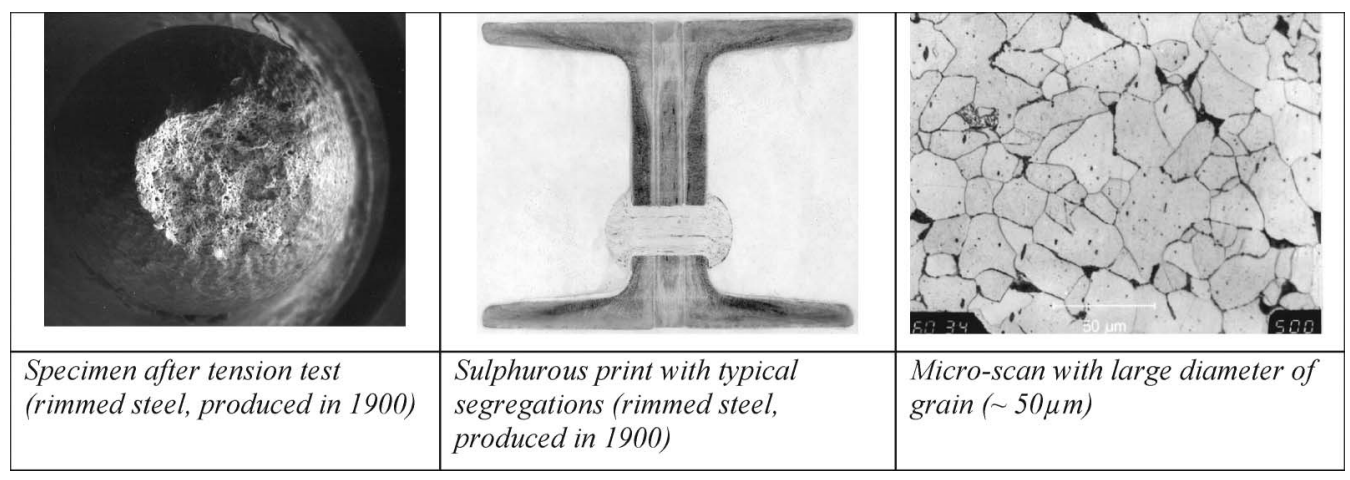

Figure 4. Characteristic of early mild iron (rimmed steel). 
Table 1. Mechanical and chemical properties of puddled iron and early mild steel (rimmed steel), based on test results (Helmerich 2005).

\begin{tabular}{|c|c|c|c|}
\hline Test, standard & $\begin{array}{l}\text { Puddled iron } \\
\left(\mathrm{N} / \mathrm{mm}^{2}\right)\end{array}$ & $\begin{array}{l}\text { Rimmed steel } \\
\left(\mathrm{N} / \mathrm{mm}^{2}\right)\end{array}$ & Comment \\
\hline Tension test: EN 10002, part 1 & & & Available tests $(\Sigma>600)$ \\
\hline Yield strength $R_{e L}$ & 203 & 229 & Specimen: \\
\hline Ultimate strength $R_{m}$ & & & Min. diameter: $5 \mathrm{~mm}$ (B5) \\
\hline Elongation $\varepsilon$, min. & 6.0 & 22 & Min. thickness: $4 \mathrm{~mm}$ \\
\hline $\max$ & 26.5 & 42 & (E4) \\
\hline \multicolumn{4}{|l|}{ Crack propagation tests, ASTM, BS } \\
\hline $\begin{array}{r}\text { Paris parameter, } \mathrm{C}, \max . \\
\text { min. }\end{array}$ & $\begin{array}{l}4.9 \times 10^{-17}(R=0.1) \\
5.7 \times 10^{-28}(R=0,5)\end{array}$ & $0.5739 \times 10^{-13}$ & $\begin{array}{l}\text { Specimen: SENB3, CT, modified CT } \\
\text { Proposed: } K_{\mathrm{th}}=2 \mathrm{MPa} \mathrm{m}{ }^{1 / 2}\end{array}$ \\
\hline $\begin{array}{r}\text { Paris parameter } \mathrm{m}, \max . \\
\text { min. }\end{array}$ & $\begin{array}{l}9.3(R=0.5) \\
3.8(R=0.3)\end{array}$ & 3.299 & $\mathrm{C}=4 \times 10^{-13}, \mathrm{~m}=3$ (upper limit) \\
\hline $\begin{array}{l}\text { Threshold of the cyclic stress intensity } \\
\text { factor } \Delta K_{\mathrm{th}}\left(\mathrm{N} / \mathrm{mm}^{3 / 2}\right)\end{array}$ & $\begin{array}{c}13.49(R=0.1) \\
6.36(R=0.5)\end{array}$ & $6.2(R=0.3)$ & \\
\hline Chemical analysis & $(\%)^{1}$ & $(\%)$ & Available tests \\
\hline $\mathrm{C}$ & $0.0032-0.15$ & $0.026-0.20$ & ${ }^{1}$ Only wet analysis possible \\
\hline $\mathrm{Si}$ & $0.003-0.42$ & $0.001-0.013$ & \\
\hline $\mathrm{S}$ & $0.0034-0.018$ & $0.063-0.176$ & $\begin{array}{l}{ }^{3} \text { If } \mathrm{N} \text { is below the soluble limit } \\
(\sim 0.014 \text {, ageing effect is neglect able })\end{array}$ \\
\hline $\mathrm{P}$ & $0.011-0.39$ & $0.009-0.136$ & \\
\hline $\mathrm{N}$ & $0.0037-0.04^{3}$ & $0.011-0.022$ & \\
\hline $\mathrm{Mn}$ & $0.054-0.11$ & $0.036-0.52$ & \\
\hline
\end{tabular}

also, the threshold stress intensity factor range $\Delta K_{\text {th }}$ of modern homogeneous steel is lower. With the test results, a statistical approach can be used to obtain characteristic values for the assessment. The probability density function should guarantee a confidence level of $95 \%$ and $5 \%$-fractile. Often the material analysis does not lead to a significant reduction in the partial safety factors used in the verifications.

The typical connection of puddled iron and rimmed steel is riveting or bolting. Some of the most famous riveted structures made from early mild steel or puddled iron are still in use today. For example, many bridges all over Europe, such as the Firth of Forth bridge in Scotland or the Eiffel Tower in Paris, both built in 1889, are famous steel structures.

Advanced material testing can contribute to FMA in Phase III. In the expert investigation, Phase III, nondestructive testing can give both, qualitative and quantitative information. If repair welding is discussed as remedial measure in Phase IV, in each single case, the weldability of old steel has to be tested in advance.

For fracture mechanic characteristic values, methods referring to US-American or British standards are used. Most commonly SENB3 (single-edged notch bending), CT (centre crack) or modified CT specimens are used. The "one specimen method" allows applying at first constant cycles to obtain the parameters $\mathrm{m}$ and $\mathrm{C}$ characterising stable crack propagation and, after that, the same specimen is used for estimation of the threshold value of the stress intensity factor range. In this second part of the test, the stress range of the cycles is decreased progressively, until the crack propagation is smaller than $10^{-8} \mathrm{~mm}$ per cycle, which is defined as the stop of the crack growth by the criterion of Taylor. This limit is defined to be the threshold value for the stress intensity factor range $\Delta K_{\mathrm{th}}$. According to BS PD 6493 the threshold value of

$$
\begin{aligned}
& R \leqslant 0.5: \quad \Delta K_{\mathrm{th}}(R)=170-214 R\left[\mathrm{~N} / \mathrm{mm}^{3 / 2}\right] \\
& R>0.5: \quad \Delta K_{\mathrm{th}}=63 \mathrm{~N} / \mathrm{mm}^{3 / 2}=2 \mathrm{MPa} \cdot \sqrt{\mathrm{m}}
\end{aligned}
$$

cover all $R$ ratios for all kinds of steel and iron. Crack growth tests in Germany and Switzerland resulted in values with more than $100 \%$ safety compared with the above given values. Thus, advanced materials investigation of the real steel can increase the estimated fatigue life significantly. When calculating the crack growth in a cross section supposed to be critical to fatigue with postulated cracks and the Paris parameters obtained in the tests, the crack reaches a critical size at a critical limit, where the remaining cross section fails due to fracture (ductile or brittle). The redundancy must be evaluated and can be increased in elements composed of two or more sections.

We propose:

1. Take specimens as large as necessary, but as small as possible.

2. No welding of puddled iron or rimmed steel.

Weldability has to be tested in each single application, e.g. in modified Tekken test or controlled thermal severity 
test (CTS). For steel with low carbon steel, $\mathrm{C}<0.18 \%$, a IIW (International Institute of welding) formula can be used. The notch impact test has been developed for welding. Performing the tests for riveted structures does not make sense since, for the behaviour of old steel, it is known that the transition temperature is at about $+10^{\circ} \mathrm{C}$.

\section{3 $S$-N-curve determination using full-scale tests}

In Phase I, the assessment procedure refers to $\mathrm{S}-\mathrm{N}$ curves for the evaluated detail. A unique $\mathrm{S}-\mathrm{N}$ curve was accepted during the past few years to be valid for old riveted structures. Many full-scale tests on original bridges and bridge elements were collected from all over the world for confirmation. During the last few decades a lot of large- or full-scale fatigue tests on original old riveted steel structures (or parts of them) have been performed. The $\mathrm{S}-\mathrm{N}$ curve corresponding to the detail category 71 was found to be safe.

Figure 5 shows the $\mathrm{S}-\mathrm{N}$ curve, chosen for the approach based on full-scale testing. For the fatigue assessment of existing welded steel structures, the detail categories given in Eurocode 3, part 1-9 and report BAM 271 (Helmerich 2005) should be used. As for the crack growth values, tests for specific structures resulted in higher values, corresponding to detail category up to 90 . Thus, investigation of the real elements can increase the estimated fatigue life significantly.

\section{Obtaining information from the structure}

\subsection{Inspection}

The guideline concentrates only on fatigue. Consequently, the information about inspection, measurement and remedial measures will focus only on possible damage caused by fatigue.

The older the bridges are, the more a bridge accumulates partial damage from service load cycles. Depending on the type of structure, the initial and fatigue damages to be evaluated during inspection can be caused by different reasons. Initial damages can be caused

- during fabrication, welding or riveting,

- due to unfavourable design with regard on fatigue, poor detailing,

- due to stresses and deformations unforeseen in design, or

- because the state of knowledge was too low.

During the very important visual inspection almost all damages are detected. In many countries, main inspections are performed every 5-6 years. In the main inspection interval, some countries have simple inspections or inspection because of special reasons. The bridge owners, such as state highway agencies or railway owners, fix the requirements in inspection guidelines. During the last few years, non-destructive testing (NDT) is being more and more applied. The guideline discusses advantages and disadvantages for different applications. Table 2 shows available NDT methods proposed for old riveted structures to be applied in different levels of the assessment.

\subsection{Measurements}

If a sufficient safety level cannot be shown by means of calculation, static and dynamic measurements shall be used. The assessment is then generally entering Phase III and aims to get detailed information from the structure. With good experience and guess, valuable measurements are possible already in Phase II.

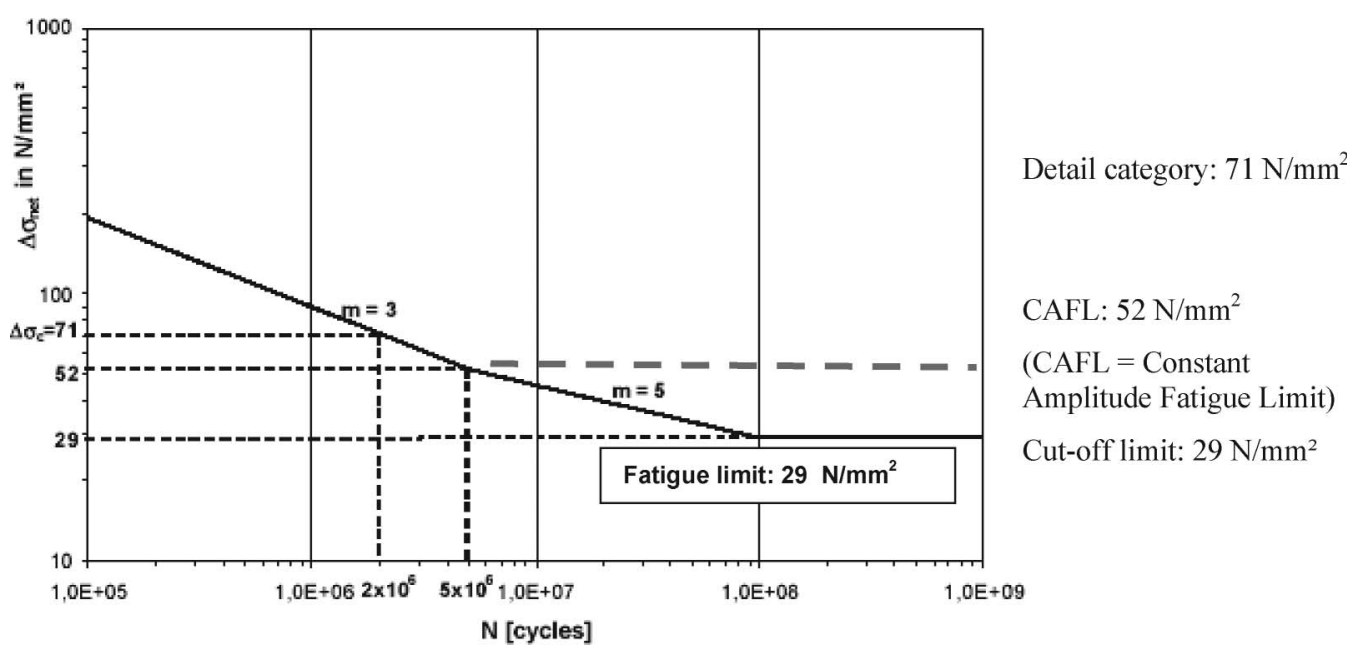

Figure 5. S-N curve proposed for fatigue assessment of riveted structures. 
The objective of a measurement is always to gain some information, either on the resistance or on the loading of the structure, in order to reduce the uncertainties associated with the static calculations made in design or in earlier fatigue assessment phases.

Measurement is appropriate in the fatigue assessment, for example if

- there are doubts about the acting static system,

- effects with consequences on the fatigue safety not known during design occurred,

- effects of increased loads or additional lanes on the fatigue safety have to be assessed, or

- secondary stresses led to fatigue damage, measurements are needed to assess the reasons.

Table 3 gives an overview on physical dimensions to measure and the sensors used.

Monitoring is repeated collection of data on the same measuring points, to obtain information about changes in the system or loading during a chosen time interval.
Monitoring is used to obtain information on timedependent processes or changes in the structure.

In general, measurements are used to obtain information from the real structure in fatigue relevant strain concentration regions with the minimum amount of sensors, e.g.:

- strain distribution in high loaded cross sections,

- function of elements, as anchors or braking trusses,

- evaluation of the actual zero axis,

- secondary stresses,

- moments in fixed supports or restraint,

- movement in bearings,

- measurement of strains in theoretical zero elements,

- local strain concentrations in connections assumed to be hinges/joints.

\section{Remedial measures}

Remedial measures in the presented guideline concentrate only on fatigue damages. Fatigue damage appears as a fatigue crack in details with the highest sensitivity to

Table 2. Non-destructive inspection tools for detection of fatigue damages.

\begin{tabular}{|c|c|c|}
\hline Method & Damage to be detected & Comment on effectiveness of the equipment \\
\hline Visual inspection & Surface cracks & With help of magnifying glass and training \\
\hline Magnetic particle test & Surface cracks & Only for magnetic materials \\
\hline Dye penetrant test & Surface cracks & $\begin{array}{l}\text { Good alternative for magnetic particle test, also for } \\
\text { non magnetic materials }\end{array}$ \\
\hline Radiography & Crack detection also in sandwiched elements & Experts with permission required \\
\hline Ultrasonic test & Only the first layer can be assessed & Not applicable for puddle iron \\
\hline Eddy current technique & Cracks in rivet holes & Not currently applied \\
\hline Acoustic emission technique & Active cracks & $\begin{array}{l}\text { Not applied for detection (insufficient research), only for } \\
\text { monitoring of detected cracks }\end{array}$ \\
\hline
\end{tabular}

Table 3. Measurement tasks and preferred sensors.

\begin{tabular}{|c|c|c|}
\hline Measurement task & Preferred sensors & Accuracy \\
\hline \multirow{3}{*}{$\begin{array}{l}\text { Local strain distribution in cross sections } \\
\text { with assumed high stress level or cross } \\
\text { sections with changes, caused by damages, }\end{array}$} & Strain gauges & $2 \mu$ \\
\hline & Mechanical strain measurement & \multirow{3}{*}{$\begin{array}{l}0.5-1 \mu \text { depending on type of fibre sensor } \\
\text { and application }\end{array}$} \\
\hline & $\begin{array}{l}\text { Fibre optical sensors (integral sensors } \\
\text { Fabry-Perot Sensors, Brag-grid sensors) }\end{array}$ & \\
\hline Actual static system & $\begin{array}{l}\text { System of strain gauges Dynamic } \\
\text { measurement system }\end{array}$ & \\
\hline Influence of temperatures & $\begin{array}{l}\text { Temperature sensor (resistance based) } \\
\text { Thermocouples (Semiconductors) }\end{array}$ & $\begin{array}{l}\sim 0.1^{\circ} \mathrm{C} \text { (depending on the max. temperature } \\
\text { range) }\end{array}$ \\
\hline Inclination & Inclinometer & $\begin{array}{l}\text { Depending on chosen max. angle } \\
\quad \text { (see producer, } \sim 0.1 \% \text { ) }\end{array}$ \\
\hline \multirow[t]{4}{*}{ Displacements or settlement } & Potentiometer & $0.1 \%$, depending on displacement \\
\hline & Inductive measurement & $0.1 \%$, depending on displacement \\
\hline & Laser based system & $0.3 \mathrm{~mm}+$ influence of measured distance \\
\hline & Hydrostatic levelling/force transducer & $\sim 0.1 \%$ depending on max. force \\
\hline Dynamic characteristics: Acceleration & Accelerators & $0.05-1 \%$ depending on force \\
\hline Eigenfrequencies & Strain transducer & \\
\hline
\end{tabular}


fatigue. Design of remedial measures has to be done carefully, because the strengthening of a detail can lead to changes in notch cases or load distribution and consequently remedial measures can lead to additional fatigue-sensitive details.

The typical fatigue details differ between welded and riveted structures. Only if the reason for a fatigue crack is identified, for example by calculations or by intensifying monitoring, then a proper solution can be applied as remedial measure. Remedial measures are:

- reducing loads;

- repair;

- strengthening;

- demolishing the structure.

A collection of typical causes for fatigue damage and a collection of details known to be sensitive to fatigue are presented. Information about cracks in bridges, given by consulters and results from full-scale fatigue testing, are taken into account and analysed regarding their possible remedial measures. Fatigue damage cases for welded structures refer to the database of the working group 5 from the International Institute of Welding. Fatigue cases for riveted structures are collected among the participating institutes, other details known from practise are welcomed.

\subsection{Case studies}

The recommendation contains in annex two case studies, one on each existing bridge type (i.e. welded and riveted). Case studies were prepared from the Netherlands and from Slovenia. In both cases, typical fatigue assessment procedures are presented.

The first case study deals with the assessment of an existing orthotropic deck in the Netherlands. After being in service for seven years, the welded orthotropic bridge structure suffered from numerous fatigue cracks in the deck below the asphalt level. Analysis of the crack locality and growing direction identified hot spots at the weld roots. Measurements confirmed that they were caused from high stress concentrations on the bridge deck over weld attaching through longitudinal rips to the decks. During the measurement, different wheel positions and different cross sections were analysed. The fatigue evaluation was done according to the fatigue design code of the Netherlands MEN 2063.

With a finite element model, the $\mathrm{S}-\mathrm{N}$ curve approach was calculated at hot spots using a bending stress range of $100 \mathrm{MPa}$ and 7.55 million cycles. This point is comparable to the with-fatigue detail category $91 \mathrm{MPa}$ for 10 million cycles, comparable to detail category $156 \mathrm{MPa}$ at 2 million cycles.
In the fracture mechanics approach a flat plate with semielliptical crack and Paris law with a simple $\mathrm{d} a / \mathrm{d} N-\Delta K$ curve was used. Different background studies were carried out for but welds. Crack growth analysis of the detected cracks with the Paris parameters for modern steel was used to identify the detail category to be $98.7 \mathrm{MPa}$ at 2 million cycles. The lifetime and reliability analysis for the obtained $\mathrm{S}-\mathrm{N}$-detail category used partial safety factors. The results were compared with three different concepts, the Eurocode 3 , average life and safe life concept, using two load models, Eurocode 3 and Dutch reference traffic load.

The second case study presented is the assessment of a riveted single span bridge in Slovenia with two equal trusses as main girders. In 2000, after over 100 years of service, the need for an assessment is that the bridge has reached the theoretically end of its design life. In this example, a calculation was done for the diagonal element of the main truss, for which it was estimated it could be the most critical regarding fatigue assessment. The assessment was based on information on number of trains and transported tons in the past and shows with a damage accumulation calculation that there is no remaining fatigue life. Due to the fact that the member chosen for the analysis cannot be considered safe any more, further measures are necessary, which were proposed in the example, too.

\section{Conclusions}

A step-by-step fatigue assessment procedure was introduced, which can be used by practising engineers for the evaluation of old steel structures-respectively, bridges, exposed to cyclic loading. The proposed assessment procedure is divided into four phases. Participation of experts, non-destructive testing methods, measurements and the analysis of the material are assigned to different phases of the assessment. The procedure is written so that a practising engineer can carry out the first phase of the assessment alone and can, upon the results, give advice to the owner. At the end of each phase, the owner has to take decisions based on a report that shall help him to find a most effective solution for the further use of the bridge. The proposed procedure is a milestone in knowledge transfer from scientific laboratory towards practising engineers.

\section{References}

Crocetti, R., Constant amplitude fatigue limit for riveted girders. Acta Polytecnica-Eurosteel 1999, 39, No. 5.

ECCS. WG-A, TC6, Assessment of Existing Steel Structures, final draft 08/ 2004 (ECCS: Brussels).

Eurocode 3. Design of Steel Structures, part 1-9, Fatigue, 2003 (CEN: Brussels).

Helmerich, R., Alte Stähle und Stahlkonstruktionen. BAM Report No. 271, Berlin, 2005, ISBN 3-86509-362-0. 
Hensen, W., Grundlagen für die Beurteilung der Weiterverwendung alter Stahlbrücken. PhD, RWTH Aachen, 1992.

International Institute of Welders, WG5. Available at www.iiw-wg5.cv. titech.ac.jp. WG5 Leader: Professor Miki, Japan.

JCSS (Joint Committee on Structural Safety). Probabilistic Assessment of Existing Structures, 2001 (Rilem publication).
Kunz, P., Probabilistisches Verfahren zur Beurteilung der Ermüdungssicherheit bestehender Brücken aus Stahl. PhD No. 1023, EPF Lausanne, 1992.

Miner, M., Cumulative damage in fatigue. Journal of Applied Mechanics, 1945, A159-A164. 